\title{
Influence of the Hole Surface Integrity on the Fatigue Strength of an Aluminium Drilled Part
}

\author{
Alexandra Lacombe ${ }^{1(\bowtie)}$, Yann Landon ${ }^{1}$, Manuel Paredes ${ }^{1}$, Clément Chirol$^{2}$, \\ and Audrey Benaben ${ }^{2}$ \\ 1 Institut Clément Ader, UMR CNRS 5312, Université de Toulouse, UPS, INSA, \\ ISAE-SUPAERO, MINES-ALBI, CNRS, 3 rue Caroline Aigle, Toulouse, France \\ alexandra. lacombe1@univ-tlse3. fr \\ 2 Airbus France, D41, 18 rue Marius Tercé, 31300 Toulouse, France
}

\begin{abstract}
Fatigue strengths of aluminium 2024-T351 open-hole specimens drilled by axial and orbital drilling processes are compared. Two drilling diameters $(\varnothing)$ are studied: $6.35 \mathrm{~mm}$ and $9.53 \mathrm{~mm}$. Surface integrity characterization tests are conducted in order to study the link between drilling processes, surface integrity and fatigue life. Fatigue test results show an increase of the fatigue life for specimens drilled by axial drilling for $\varnothing=9.53 \mathrm{~mm}$ and no significant difference in fatigue life between the two drilling processes for $\emptyset=6.35 \mathrm{~mm}$. Surface integrity results show no impact of the roughness on the fatigue strength but a potential positive influence of the hole microhardness on the fatigue life.
\end{abstract}

Keywords: Drilling process $\cdot$ Fatigue life $\cdot$ Surface integrity $\cdot$ Aluminium alloy

\section{Introduction}

Parts of aircraft are mostly assembled using fasteners (rivets or screws) introduced into holes machined by drilling. Assembling an aircraft may require several hundred thousand to several million drilling operations depending on the aircraft size [1]. These holes for fastening are critical areas where fatigue damage can be initiated because they are areas of high stress concentration. The drilling procedure used for the machining of the fastening holes can affect the fatigue life of the drilled part [2-5]. Indeed, according to the procedure, the part undergoes different thermo-mechanical loading that can induce differences in the surface integrity of the hole (roughness, residual stress, hardness, etc.) [6].

The most common process for machining a fastening hole in the aircraft industry is axial drilling. This process involves the use of a rotating drill bit that feeds linearly into the part. Although this process is well known, it has certain drawbacks. As an example, axial drilling may result in the formation of a burr on the face of the part where the tool exits, because of the high axial forces involved [7]. So, the parts require a deburring operation after the drilling. 
Orbital drilling involves the use of a rotating end mill travelling on a helical path into the part. With this process, the cutting process is intermittent and the material is removed in the form of small chips. Orbital drilling has many advantages [8]. It avoids the formation of burrs, it allows better chip evacuation and less heating, and gives holes with high surface quality in a near dry environment and in a one-step operation [9]. However, the impact of this drilling process on the fatigue strength of the part is not well known.

Thus, the aim of this work is to compare the fatigue strength of open-hole specimens drilled by axial and orbital drilling for the aluminium alloy 2024-T351, which is commonly used in the aircraft industry for its low density and its high fatigue performance. Moreover, in order to identify the parameters that control the fatigue life, the impact of the drilling process on the surface integrity of the hole (roughness and Vickers microhardness) is also investigated.

\section{Experimental Work}

\subsection{Fatigue Tests}

Fatigue specimens were open-hole T-Type elementary specimens machined from 2024T351 aluminium plate in such a way that their longitudinal axis was aligned with the rolling direction of the plate. The specimen width was three times the nominal diameter and its length was $200 \mathrm{~mm}$ (Fig. 1). The holes were obtained by drilling then deburring. Two nominal drilling diameters $(\varnothing)$ were studied: $6.35 \mathrm{~mm}$ and $9.53 \mathrm{~mm}$. For $\varnothing=$ $9.53 \mathrm{~mm}$, the specimen thickness was $10 \mathrm{~mm}$. For $\varnothing=6.35 \mathrm{~mm}$, three thicknesses were studied: $3.175 \mathrm{~mm}, 6.35 \mathrm{~mm}$ and $10 \mathrm{~mm}$.

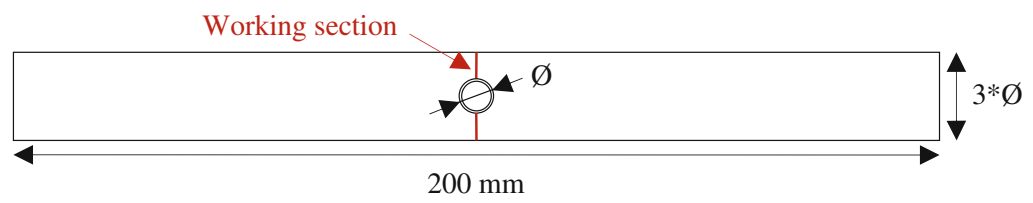

Fig. 1. Overall geometry of fatigue specimens

Axial and orbital drilling processes were studied. The cutting parameters and tools used for each drilling process and for each diameter are presented in Table 1.

The cutting parameters used for axial drilling were the optimum parameters provided by the tool manufacturer and those used for orbital drilling were determined through a specific Tool-Material Pair. External MQL lubrication was used for both drilling processes.

Fatigue tests were performed in a Schenk servo hydraulic machine using a sinusoidal cyclic load with a load ratio of 0.1 and a frequency of $20 \mathrm{~Hz}$. Fatigue tests were carried out for various load levels in order to obtain Wöhler curves.

Fatigue test results are presented in Fig. 2 as semi-log $(\mathrm{S}-\mathrm{N})$ curves. The stress S corresponds to the maximum stress reached in the working section during a fatigue cycle. In 
Table 1. Drilling cutting parameters and tools

\begin{tabular}{l|l|l|l|l}
\hline & \multicolumn{2}{l|}{$\varnothing=6.35 \mathrm{~mm}$} & $\varnothing=9.53 \mathrm{~mm}$ & \\
\cline { 2 - 5 } & Axial drilling & Orbital drilling & Axial drilling & Orbital drilling \\
\hline $\mathrm{N}_{\text {spindle }}(\mathrm{rpm})$ & 9000 & 40000 & 4000 & 40000 \\
\hline $\mathrm{N}_{\text {orb }}(\mathrm{rpm})$ & - & 1500 & - & 1500 \\
\hline $\mathrm{V}_{\mathrm{fa}}(\mathrm{mm} / \mathrm{min})$ & 900 & 60 & 400 & 60 \\
\hline $\mathrm{V}_{\mathrm{c}}(\mathrm{m} / \mathrm{min})$ & 180 & 610 & 120 & 1005 \\
\hline $\mathrm{f}_{\mathrm{a}}(\mathrm{mm} / \mathrm{rev})$ & 0.1 & 0.0015 & 0.1 & 0.0015 \\
\hline Tool & $\begin{array}{l}\text { Tungsten carbide } \\
\text { drill }\end{array}$ & $\begin{array}{l}\text { 4-tooth tungsten } \\
\text { carbide end mill }\end{array}$ & $\begin{array}{l}\text { Step tungsten } \\
\text { carbide diamond } \\
\text { coated drill }\end{array}$ & $\begin{array}{l}\text { 4-tooth tungsten } \\
\text { carbide end mill }\end{array}$ \\
\hline
\end{tabular}

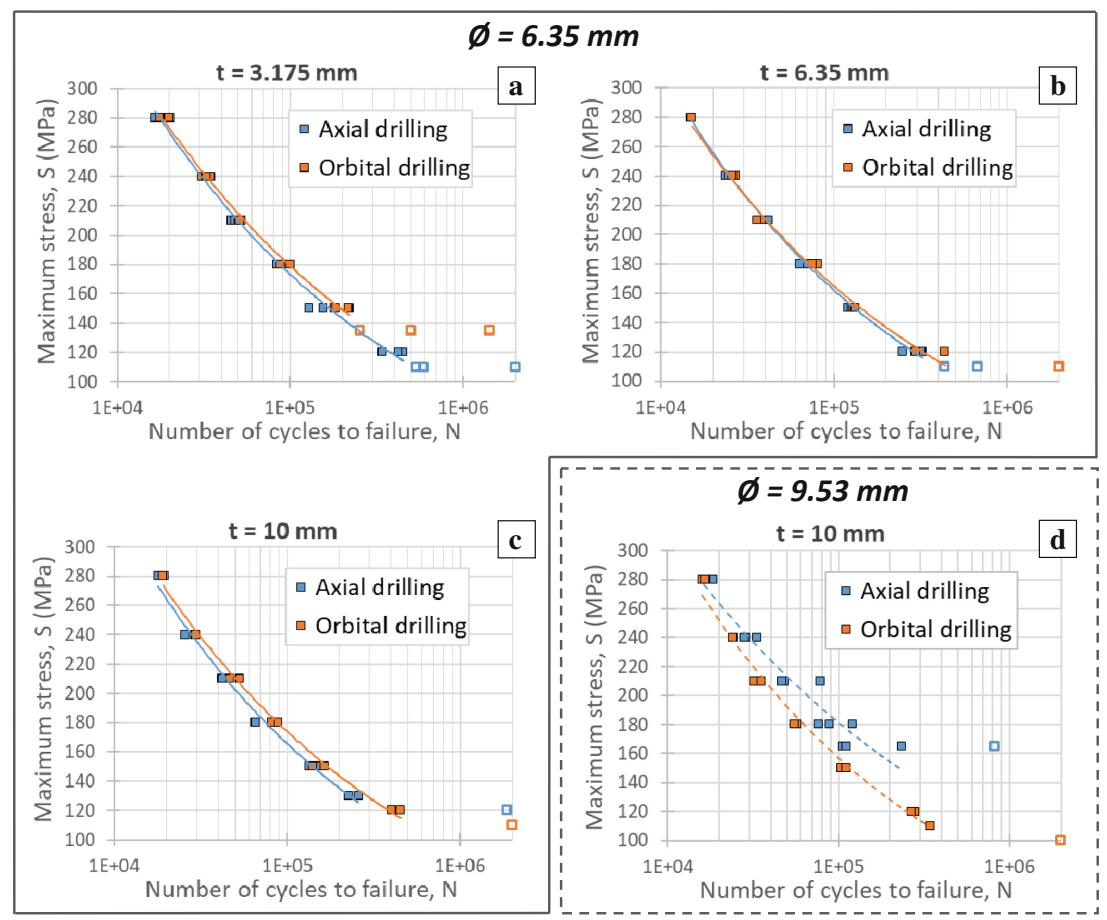

Fig. 2. Wohler curves for $\varnothing=6.35 \mathrm{~mm}(\mathrm{a}, \mathrm{b}, \mathrm{c})$ and $\varnothing=9.53 \mathrm{~mm}$ (d)

the aircraft industry, the fatigue performance of a structure is commonly evaluated by the fatigue quality index, which corresponds to the stress $S$ associated with a forecast fatigue life of 100000 cycles. Fatigue quality indexes were determined for all configurations from Wöhler curves and are shown in Fig. 3. 
Fatigue test results obtained for $\varnothing=6.35 \mathrm{~mm}$ show that the specimen thickness and the drilling process have negligible influence on the fatigue strength. Except for $t$ $=3.175 \mathrm{~mm}$, for the lowest stress levels, a gain in fatigue life is observed for orbital drilling compared to axial drilling. In contrast, fatigue test results obtained for $\varnothing=$ $9.53 \mathrm{~mm}$ show an increase in fatigue life for the specimens obtained by axial drilling for all stress levels. For this drilling configuration, a gain in the fatigue quality index of $15 \%$ is observed and an even greater gain is observed for the stress corresponding to the fatigue limit.
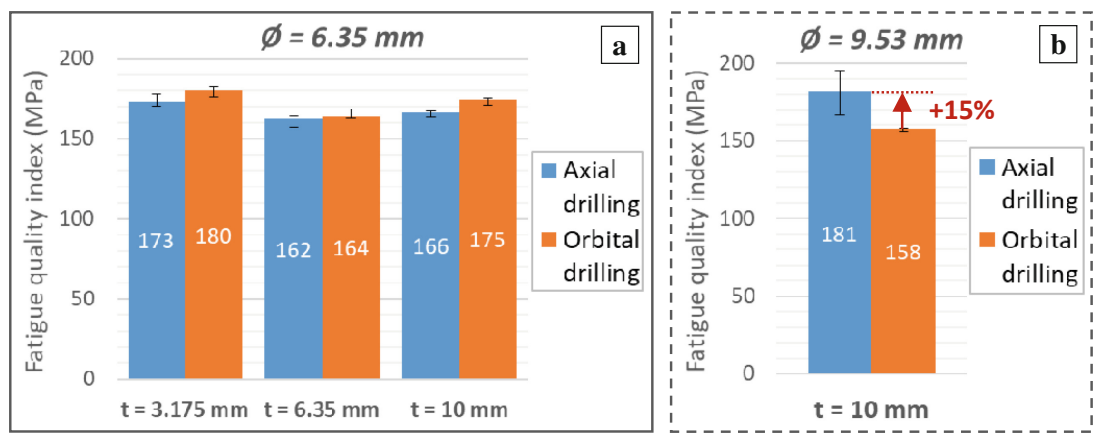

Fig. 3. Fatigue quality indexes for $\varnothing=6.35 \mathrm{~mm}$ (a) and $\varnothing=9.53 \mathrm{~mm}$ (b)

\subsection{Surface Integrity Characterization}

In order to identify the parameters that control the fatigue life, a test campaign was conducted to characterize the surface integrity of the holes. Roughness and microhardness were measured.

Roughness measurements were performed along the height of the hole with a profilometer with a cut-off length of $0.8 \mathrm{~mm}$. The results are presented in Fig. 4. For all specimens where orbital drilling was used, the roughness average ( $\mathrm{Ra}$ ) was lower than that of specimens drilled with axial drilling, which is consistent with previous works [3]. However, no correlation could be established between these results and fatigue test results. This was probably related to the relatively low Ra values measured compared to the aeronautical specification $(\mathrm{Ra}<1.6)$.

Vickers microhardness measurements were made on the hole surface with a load of $1 \mathrm{kgf}$ and an indentation time of $15 \mathrm{~s}$. Because of the cylindrical shape of the hole, a corrective factor was applied to the results as recommended by ASTM E92. The results are presented in Fig. 5. For $\varnothing=6.35 \mathrm{~mm}$, holes obtained by axial and orbital drilling had similar microhardness levels whereas, for $\emptyset=9.53 \mathrm{~mm}$, a significant difference in microhardness level was observed between the two drilling processes. For this diameter, a gain of 29\% in microhardness level was observed for axial drilling. These results seem to show a correlation of fatigue test results with microhardness measurements. Indeed, the increase in microhardness for axial drilling at $\varnothing=9.53 \mathrm{~mm}$ may explain the gain in fatigue life observed for the same configuration. 

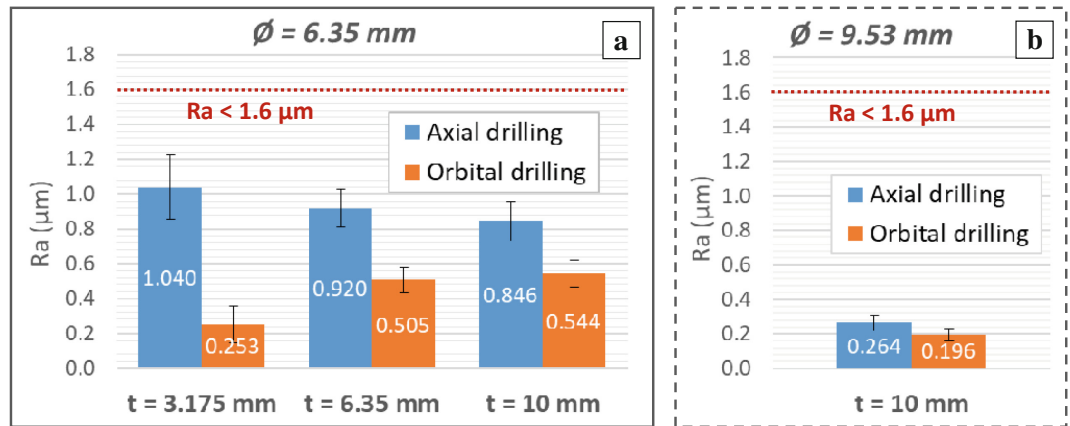

Fig. 4. Roughness average measurements for $\emptyset=6.35 \mathrm{~mm}$ (a) and $\varnothing=9.53 \mathrm{~mm}$ (b)
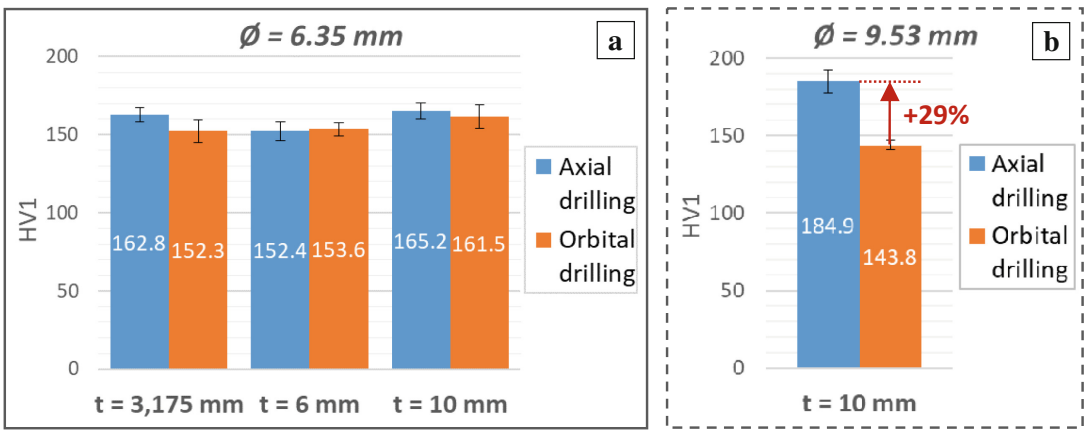

Fig. 5. Vickers microhardness measurements for $\varnothing=6.35 \mathrm{~mm}$ (a) and $\varnothing=9.53 \mathrm{~mm}$ (b)

\section{Discussion and Conclusions}

A fatigue test campaign was carried out in order to compare the fatigue strength of aluminium 2024-T351 open-hole specimens drilled by the axial and orbital drilling processes. The Wöhler curves obtained show a slight fatigue life difference between specimens drilled by axial and orbital drilling for $\varnothing=6.35 \mathrm{~mm}$ and a significant gain in fatigue life for the specimens drilled by the axial technique for $\varnothing=9.53 \mathrm{~mm}$. The specimen thickness seems to have negligible influence on the fatigue strength.

Roughness measurements show no correlation between the hole roughness and the fatigue life of the drilled part. This is related to the low Ra values measured and is in accordance with the Kitagawa diagram [10], which establishes that, below a certain defect size, the fatigue limit is no longer sensitive to the defect size.

Vickers microhardness measurements seem to show a significant influence of the hole microhardness on the fatigue life of the part. The difference in microhardness level observed for $9.53 \mathrm{~mm}$ diameter holes may be related to the difference between the thermomechanical loads experienced by the machined surfaces in the two drilling processes. As the temperatures reached during an aluminium drilling operation are not high enough to induce a phase transformation [1], the increase in microhardness may be related to strain hardening of the hole sub-surface induced by the mechanical loading, or 
to precipitation hardening induced by the thermal loading [11]. In order to study these aspects, the mechanical and thermal loads involved during drilling and the material microstructure in the hole edge area will be studied.

Residual stresses present in the hole edge area are cited in the literature [12] as having an influence on fatigue strength, so this aspect of surface integrity will also be investigated. However, since the material depth affected by residual stresses after an aluminium drilling operation is relatively small (from several tens to several hundreds of microns) [13], current techniques for residual stress evaluation (X-ray diffraction, incremental hole drilling, etc.) cannot be used. So, a new strategy for residual stress evaluation will be considered.

\section{References}

1. Girot, F., et al.: Perçage des structures aéronautiques: Les résultats du projet MEDOC, $1^{\mathrm{er}}$ colloque Aquitaine - Québec-Mécanique des Matériaux et des Structures pour l'Aéronautique, July 2008

2. Elajrami, M., Benguediab, M., Ronald, G.: Effect of various drilling procedures on the fatigue life of rivet holes. Synthèse: Revue des Sciences et de la Technologie 19, 67-75 (2008)

3. Sun, D., Lemoine, P., Keys, D., Doyle, P., Malinov, S., Zhao, Q., Qin, X., Jin, Y.: Hole-making processes and their impacts on the microstructure and fatigue response of aircraft alloys. Int. J. Adv. Manuf. Technol. 94(5-8), 1719-1726 (2018)

4. Ralph, W.C., Jonhson, W.S., Makeev, A., James, C., Newman, J.: Fatigue performance of production-quality aircraft fastener holes. Int. J. Fatigue 29(7), 1319-1327 (2007)

5. Everett, R.A.: The effect of hole quality on the fatigue life of 2024-T3 aluminum alloy sheet (2004)

6. Ralph, W.C., Johnson, W.S., Toivonen, P., Makeev, A., Newman, J.: Effect of various aircraft production drilling procedures on hole quality. Int. J. Fatigue 28(8), 943-950 (2006)

7. Abdelhafeez, A.M., Soo, S.L., Aspinwall, D.K., Dowson, A., Arnold, D.: Burr formation and hole quality when drilling titanium and aluminium alloys. Procedia CIRP 37, 230-235 (2015)

8. Pereira, R.B.D., Brandao, L.C., De Paiva, A.P., Ferreira, J.R., Davim, J.P.: A review of helical milling process. Int. J. Mach. Tools Manuf. 120, 27-48 (2017)

9. Ni, W.: Orbital drilling of aerospace materials. SAE Technical Paper (2007)

10. Kitagawa, H., Takahashi, S.: Applicability of fracture mechanics to very small cracks or the cracks in the early stage. In: International Conference on Mechanical Behaviour of Materials, Boston, pp. 627-631 (1976)

11. Choo, V.K.S., Reinhall, P.G., Ghassaei, S.: Effect of high rate deformation induced precipitation hardening on the failure of aluminium rivets. J. Mater. Sci. 24(2), 599-608 (1989)

12. Lai, M.O., Oh, J.T., Nee, A.Y.C.: Fatigue properties of holes with residual stresses. Eng. Fract. Mech. 45(5), 551-557 (1993)

13. Federal Aviation Administration. Assessment of residual stresses and hole quality on the fatigue behavior of aircraft structural joints (2009) 
Open Access This chapter is licensed under the terms of the Creative Commons Attribution 4.0 International License (http://creativecommons.org/licenses/by/4.0/), which permits use, sharing, adaptation, distribution and reproduction in any medium or format, as long as you give appropriate credit to the original author(s) and the source, provide a link to the Creative Commons license and indicate if changes were made.

The images or other third party material in this chapter are included in the chapter's Creative Commons license, unless indicated otherwise in a credit line to the material. If material is not included in the chapter's Creative Commons license and your intended use is not permitted by statutory regulation or exceeds the permitted use, you will need to obtain permission directly from the copyright holder.

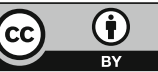

